\title{
Research on the Index System of Comprehensive Quality Evaluation for Marine College Students
}

\author{
Xiuping Sui ${ }^{1, a}$ Xuling $\mathrm{Hu}^{2, b}$ \\ Shandong Jiaotong University Maritime College, Shandong, China \\ Whsui@.163com
}

Key words: Marine college students, analytic hierarchy process, quality

\begin{abstract}
With the coming of the world economic integration, the position of the shipping industry is becoming more and more important in the world economy. it is particularly important for marine College to train the social demand, high-quality shipping talent. At present, navigation class colleges and universities students, in the face of increasingly heavy study pressure of the school, and facing hard career after graduation allocation, insecurity and long time drift pressure, more and more students would not like to attend Class-A certificate competency test, and then give up the profession of the crew. By using the analytic hierarchy process, this paper analyzes the comprehensive quality of marine college students, and provides reference for the management of the higher education institutions and enterprises.
\end{abstract}

\section{Introduction:}

With the coming of the world economic integration, the position of the shipping industry is becoming more and more important in the world economy. it is particularly important for marine College to train the social demand, high-quality shipping talent. At present, navigation class colleges and universities students, in the face of increasingly heavy study pressure of the school, and facing hard career after graduation allocation, insecurity and long time drift pressure, more and more students would not like to attend Class-A certificate competency test, and then give up the profession of the crew. By using the analytic hierarchy process, this paper analyzes the comprehensive quality of marine college students, and provides reference to the management of the higher education institutions and enterprises.

The paper aims to improve the overall quality of maritime students for the main purpose from the five aspects of professional knowledge, English level, practical skills, psychological quality and physical quality to establish the system frame of maritime students comprehensive quality analysis, and the paper optimizes the nautical college students' comprehensive quality as the ultimate goal to establish evaluation index system.

\section{Composition and weight of comprehensive quality evaluation index system for Marine College Students}

According to the questionnaire, the index system is established, such as professional knowledge, psychological quality, practical skills, physical quality, English level. Professional knowledge includes navigation, collision avoidance, cargo and constructure, ship management and meteorological knowledge;Psychological quality, includes intelligence and ability factors, 
psychological status, non intellectual factors and social adaptation factors;Practical skills includes sailor craft, instrument operation, GMDSS operation, basic safe operation, etc.;Physical qualities includes endurance, strength, agility, speed, and flexibility;English includes listening, speaking, reading and writing.

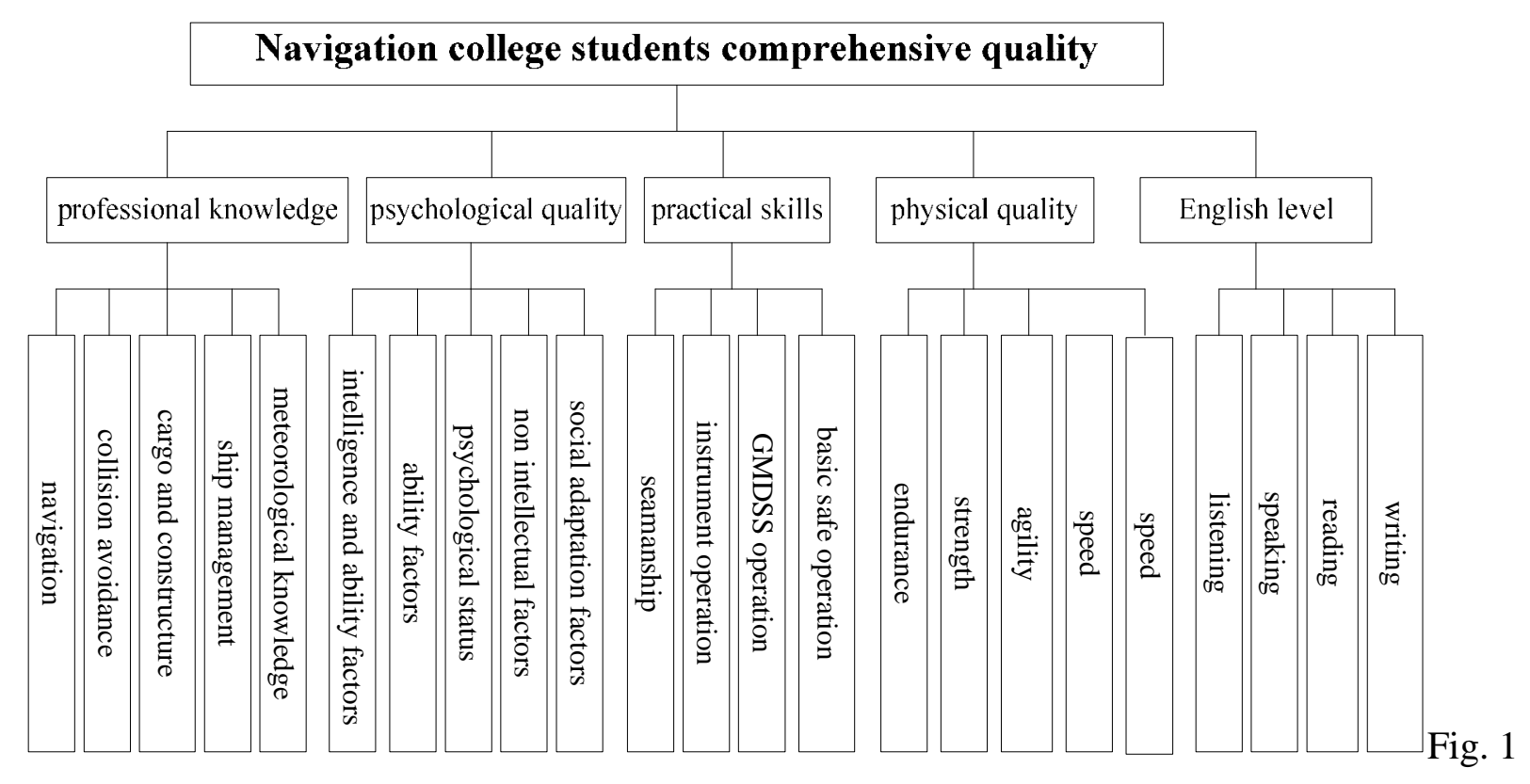

Comprehensive Quality Evaluation for Marine College Students

\section{Setup Judgment Matrices}

The hierarchical structure of this paper is based on the evaluation index system of the crew's quality under the emergency conditions established above, and test the consistency, and weigh the value of each index layer as follow:

A0

$\left[\begin{array}{ccccc}1 & 2 & 3 & 3 & 5 \\ 1 / 2 & 1 & 2 & 3 & 4 \\ 1 / 3 & 1 / 2 & 1 & 2 & 4 \\ 1 / 3 & 1 / 3 & 1 / 2 & 1 & 3 \\ 1 / 5 & 1 / 4 & 1 / 4 & 1 / 3 & 1\end{array}\right]$

$\mathrm{W}=(0.3970,0.2653,0.1710,0.1128,0.0539)$

$\lambda_{\max }=5.1516, \mathrm{CI}=0.03791, \mathrm{CR}=0.03385<1$

A1 


$\left[\begin{array}{ccccc}1 & 2 & 3 & 3 & 5 \\ 1 / 2 & 1 & 2 & 3 & 4 \\ 1 / 3 & 1 / 2 & 1 & 2 & 4 \\ 1 / 3 & 1 / 3 & 1 / 2 & 1 & 3 \\ 1 / 5 & 1 / 4 & 1 / 4 & 1 / 3 & 1\end{array}\right]$

A2

$\left[\begin{array}{cccc}1 & 2 & 3 & 4 \\ 1 / 2 & 1 & 2 & 3 \\ 1 / 3 & 1 / 2 & 1 & 2 \\ 1 / 4 & 1 / 3 & 1 / 2 & 1\end{array}\right]$

A3

$\left[\begin{array}{cccc}1 & 2 & 3 & 4 \\ 1 / 2 & 1 & 2 & 3 \\ 1 / 3 & 1 / 2 & 1 & 2 \\ 1 / 4 & 1 / 3 & 1 / 2 & 1\end{array}\right]$

A4

$\left[\begin{array}{ccccc}1 & 2 & 3 & 4 & 4 \\ 1 / 2 & 1 & 2 & 4 & 4 \\ 1 / 3 & 1 / 2 & 1 & 3 & 3 \\ 1 / 4 & 1 / 4 & 1 / 3 & 1 & 1 \\ 1 / 4 & 1 / 4 & 1 / 3 & 1 & 1\end{array}\right]$

A5

$\left[\begin{array}{ccccc}1 & 2 & 3 & 4 & 5 \\ 1 / 2 & 1 & 3 & 4 & 4 \\ 1 / 3 & 1 / 3 & 1 & 2 & 3 \\ 1 / 4 & 1 / 4 & 1 / 2 & 1 & 2 \\ 1 / 5 & 1 / 4 & 1 / 3 & 1 / 2 & 1\end{array}\right]$

$\mathrm{A} 1: \mathrm{W}(1)=(0.4054,0.2675,0.1627,0.0990,0.0653)$,

$\mathrm{A} 2: \mathrm{W}(2)=(0.4668,0.2776,0.1603,0.0953)$,

$\mathrm{A} 3: \mathrm{W}(3)=(0.4668,0.2776,0.1603,0.0953)$,

$\mathrm{A} 4: \mathrm{W}(4)=(0.3954,0.2996,0.1587,0.0732,0.0732)$

A5 $: \mathrm{W}(5)=(0.4087,0.2962,0.1447,0.0901,0.0602)$

$\mathrm{A} 1: \lambda_{\max }=5.1019, \mathrm{CI}=0.02547, \mathrm{CR}=0.0227<0.1$

$\mathrm{A} 2: \lambda_{\max }=4.0310, \mathrm{CI}=0.01033, \mathrm{CR}=0.0115<0.1$ 
$\mathrm{A} 3: \lambda_{\max }=4.0310, \mathrm{CI}=0.01033, \mathrm{CR}=0.0115<0.1$

$\mathrm{A} 4: \lambda_{\max }=5.1648, \mathrm{CI}=0.04120, \mathrm{CR}=0.03679<0.1$

$\mathrm{A} 5: \lambda_{\max }=5.1330, \mathrm{CI}=0.03325, \mathrm{CR}=0.02969<0.1$

We get the consistency

\section{conclusion}

In the comprehensive quality of marine professional college students, the two level indicators include professional knowledge, psychological quality, practical skills, physical quality, English level.In all the indicators, the professional knowledge to occupy the most important position, because only know the professional knowledge, in the future to be competent for the job. English level occupies second, as a navigation professional college students, must have a certain ability to read and write. Of course, as a marine professional college students should also have a certain psychological quality and physical quality.

In the third grade indexes and professional knowledge including navigation, collision avoidance, freight and structure, ship management, weather and other knowledge, navigation is the most important. In the psychological quality, the factor of intelligence and ability is more important than other factors. In practical skills, the sailor craft is the most important; physical fitness, including endurance, strength, agility, speed, flexibility, endurance and strength than speed and flexibility is more important. English listening and speaking ability is more important.

\section{References}

[1] http://thequalityportal.com/q_ahp.htm. Retrieved 2007-08-21.

[2] European Management Journal Volume [J] :21, Issue:3, June, 2003.

[3] Michael Armstrong and Angela Baron. PerformanceManagement [M] .London: The Cromwell Press.1998. 